\title{
Some fixed point results for multi-valued mappings in $b$-metric spaces
}

\author{
Marwan Amin Kutbi ${ }^{1}$, Erdal Karapınar ${ }^{2,3 *}$, Jamshaid Ahmad ${ }^{4}$ and Akbar Azam ${ }^{4}$
}

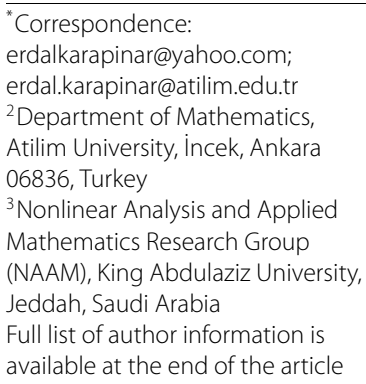

${ }^{3}$ Nonlinear Analysis and Applied Mathematics Research Group (NAAM), King Abdulaziz University, Jeddah, Saudi Arabia Full list of author information is available at the end of the article

\begin{abstract}
The aim of this paper is to establish some fixed point theorems for set-valued mappings in the context of $b$-metric spaces. The proposed theorems expand and generalize several well-known comparable results in the literature. An example is also given to support our main result.
\end{abstract}

MSC: $46540 ; 47 \mathrm{H} 10 ; 54 \mathrm{H} 25$

Keywords: Hausdorff metric; set-valued mapping; fixed point; $b$-metric space

\section{Introduction and preliminaries}

The notion of metric space, introduced by Fréchet in 1906, is one of the cornerstones of not only mathematics but also several quantitative sciences. Due to its importance and application potential, this notion has been extended, improved and generalized in many different ways. An incomplete list of the results of such an attempt is the following: quasimetric space, symmetric space, partial metric space, cone metric space, G-metric space, probabilistic metric space, fuzzy metric space and so on.

In this paper, we pay attention to the concept of $b$-metric space. The notion of $b$-metric space was introduced by Czerwik [1] in 1993 to extend the notion of metric space. In this interesting paper, Czerwik [1] observed a characterization of the celebrated Banach fixed point theorem [2] in the context of complete $b$-metric spaces. Following this pioneer paper, several authors have devoted their attention to research the properties of a $b$-metric space and have reported the existence and uniqueness of fixed points of various operators in the setting of $b$-metric spaces (see, e.g., [3-12] and some reference therein).

The aim of this paper is to generalize various known results proved by Kikkawa and Suzuki [13], Mot and Petrusel [14], Dhompongsa and Yingtaweesittikul [15] to the case of $b$-metric spaces and give an example to illustrate our main results.

Definition 1 Let $X$ be any nonempty set. An element $x$ in $X$ is said to be a fixed point of a multi-valued mapping $T: X \rightarrow 2^{X}$ if $x \in T x$, where $2^{X}$ denotes the collection of all nonempty subsets of $X$.

Let $(X, d)$ be a metric space. Let $C B(X)$ be the collection of all nonempty, closed and bounded subsets of $X$. In the sequel, we use the following notations:

$$
d(a, A)=\inf \{d(a, x): x \in A\}
$$

๑2014 Kutbi et al.; licensee Springer. This is an Open Access article distributed under the terms of the Creative Commons Attribution License (http://creativecommons.org/licenses/by/2.0), which permits unrestricted use, distribution, and reproduction in any medium, provided the original work is properly cited. 


$$
\begin{aligned}
& \delta(A, B)=\sup \{d(a, B): a \in A\}, \\
& \delta(B, A)=\sup \{d(b, A): b \in B\}
\end{aligned}
$$

and

$$
H(A, B)=\max \{\delta(A, B), \delta(B, A)\}
$$

for any $A, B \in C B(X)$.

Notice that $H$ is called the Hausdorff metric induced by the metric $d$.

We start with recalling some basic definitions and lemmas on $b$-metric spaces. The definition of a $b$-metric space is given by Czerwik [1] (see also [4, 5]) as follows.

Definition 2 Let $X$ be a nonempty set $X$ and $s \geq 1$ be a given real number. A function $d: X \times X \rightarrow \mathbb{R}_{+}$is called a $b$-metric provided that, for all $x, y, z \in X$,

$\left(\mathrm{bms}_{1}\right) d(x, x)=0$,

$\left(\mathrm{bms}_{2}\right) d(x, y)=d(y, x)$,

$\left(\mathrm{bms}_{3}\right) \quad d(x, z) \leq s(d(x, y)+d(y, z))$.

Note that a (usual) metric space is evidently a $b$-metric space. However, Czerwik $[1,4]$ showed that a $b$-metric on $X$ need not be a metric on $X$ (see also $[5,16,17])$. The following example shows that a $b$-metric on $X$ need not be a metric on $X$.

Example 1 (cf. [18]) Let $X=\{a, b, c\}$ and $d(a, c)=d(2, c)=m \geq 2, d(c, b)=d(b, a)=$ $d(b, c)=d(c, b)=1$, and $d(a, a)=d(b, b)=d(c, c)=0$. Then $d(x, y) \leq \frac{m}{2}[d(x, z)+d(z, y)]$ for all $x, y, z \in X$. If $m>2$, then the ordinary triangle inequality does not hold.

Let $(X, d)$ be a $b$-metric space. We cite the following lemmas from Czerwik $[1,4,5]$ and Singh et al. [18].

Lemma 1 Let $(X, d)$ be a $b$-metric space. For any $A, B \in C B(X)$ and any $x, y \in X$, we have the following:

(1) $d(x, B) \leq d(x, b)$ for any $b \in B$,

(2) $d(x, B) \leq H(A, B)$,

(3) $d(x, A) \leq s(d(x, y)+d(y, B))$.

Remark 1 Let $(X, d)$ be a $b$-metric space and $A$ be a nonempty set in $(X, d)$ and $x \in A$, then we have

$$
d(x, A)=0 \quad \Leftrightarrow \quad x \in \bar{A}=A,
$$

where $\bar{A}$ denotes the closure of $A$ with respect to the induced metric $d$. Note that $A$ is closed in $(X, d)$ if and only if $\bar{A}=A$.

Remark 2 The mapping $d$ in a $b$-metric space $(X, d)$ need not be jointly continuous (see, e.g., $[19,20])$. 
Lemma 2 Let $A$ and $B$ be nonempty closed and bounded subsets of a $b$-metric space $(X, d)$ and $q>1$. Then, for all $a \in A$, there exists $b \in B$ such that $d(a, b) \leq q H(A, B)$.

Lemma 3 Let $(X, d)$ be a b-metric space. Let $A$ and $B$ be in $C B(X)$. Then, for each $\alpha>0$ and for all $b \in B$, there exists $a \in A$ such that $d(a, b) \leq H(A, B)+\alpha$.

The following result was proved by Aydi et al. in [21].

Theorem 1 Let $(X, d)$ be a complete b-metric space and let $F: X \rightarrow C B(X)$ be a multivalued mapping such that for all $x, y \in X$,

$$
H(F x, F y) \leq r M(x, y)
$$

where $0 \leq r<\frac{1}{s^{2}+s}<1$ and

$$
M(x, y)=\max \{d(x, y), d(x, F x), d(y, F y), d(x, F y), d(y, F x)\} .
$$

Then $F$ has a fixed point in $X$, that is, there exists $u \in X$ such that $u \in F u$.

The following preliminary lemma will play a crucial role in the sequel.

Lemma 4 [22] Let $(X, d)$ be a complete b-metric space and let $\left\{x_{n}\right\}$ be a sequence in $X$ such that $d\left(x_{n+1}, x_{n+2}\right) \leq \beta d\left(x_{n}, x_{n+1}\right)$ for all $n=0,1,2, \ldots$, where $0 \leq \beta<1$. Then $\left\{x_{n}\right\}$ is a Cauchy sequence in $X$ provided that $s \beta<1$.

\section{Main results}

In this section we state and prove our main results. Inspired the results of Aydi et al. [21], we establish a Kikkawa and Suzuki type fixed point theorem in the framework of $b$-metric spaces as follows.

Theorem 2 Let $(X, d)$ be a complete b-metric space and let $F: X \rightarrow C B(X)$ be a multivalued mapping. Then, for $s \geq 1$, define a strictly decreasing function $\sigma$ from $[0,1)$ onto $\left(\frac{1}{2}, 1\right]$ by $\sigma(r)=\frac{1}{(1+s r)}$, where $r<\frac{1}{s^{2}+s}<1$, such that

$$
\sigma(r) d(x, F x) \leq s d(x, y) \quad \Longrightarrow \quad H(F x, F y) \leq r d(x, y)
$$

for all $x, y \in X$. Then there exists $u \in X$ such that $u \in F u$.

Proof If $d(x, y)=0$, then by (2.1) we deduce that $x=y$ is a fixed point of $F$. Hence the proof is completed. Thus, throughout the proof, we assume that $d(x, y)>0$ for all $x, y \in X$. Take

$$
\alpha=\frac{1}{2}\left(\frac{1}{s^{2}+s}-r\right)
$$

and

$$
\beta=r+\alpha=\frac{1}{2}\left(\frac{1}{s^{2}+s}+r\right) .
$$


Due to the assumption $r<\frac{1}{s^{2}+s}$, we conclude that $\alpha>0$ and $0<\beta<1$. Let $x_{0} \in X$ be arbitrary and $x_{1} \in F x_{0}$. Owing to (2.1), we have

$$
\sigma(r) d\left(x_{0}, F x_{0}\right) \leq \sigma(r) d\left(x_{0}, x_{1}\right) \leq s d\left(x_{0}, x_{1}\right)
$$

which yields that

$$
H\left(F x_{0}, F x_{1}\right) \leq r d\left(x_{0}, x_{1}\right)
$$

By Lemma 3, there exists $x_{2} \in F x_{1}$. Now, by using the previous inequality, we obtain

$$
d\left(x_{1}, x_{2}\right) \leq H\left(F x_{0}, F x_{1}\right)+\alpha d\left(x_{0}, x_{1}\right) \leq r d\left(x_{0}, x_{1}\right)+\alpha d\left(x_{0}, x_{1}\right)=\beta d\left(x_{0}, x_{1}\right),
$$

where $\beta=r+\alpha$. On the other hand, we have

$$
\begin{aligned}
\sigma(r) d\left(x_{1}, F x_{1}\right) & \leq \sigma(r) d\left(x_{1}, x_{2}\right) \\
& \leq d\left(x_{1}, x_{2}\right) \\
& \leq s d\left(x_{1}, x_{2}\right) .
\end{aligned}
$$

Thus, we derive that

$$
H\left(F x_{1}, F x_{2}\right) \leq r d\left(x_{1}, x_{2}\right)
$$

by condition (2.1). Employing Lemma 3 again, there exists $x_{3} \in F x_{2}$ such that

$$
d\left(x_{2}, x_{3}\right) \leq H\left(F x_{1}, F x_{2}\right) \leq r d\left(x_{1}, x_{2}\right)+\alpha d\left(x_{1}, x_{2}\right) \leq \beta d\left(x_{1}, x_{2}\right) .
$$

Continuing in this way, we can construct a sequence $\left\{x_{n}\right\}$ in $X$ such that $x_{n+1} \in F x_{n}$ and

$$
d\left(x_{n}, x_{n+1}\right) \leq \beta^{n} d\left(x_{0}, x_{1}\right)
$$

for all $n \in \mathbb{N}$. Having in mind $s \geq 1$ together with $\beta=\frac{1}{2}\left(\frac{1}{s^{2}+s}+r\right)$ and $r<\frac{1}{s^{2}+s}$, one can easily obtain that $s \beta<1$. Taking Lemma 4 into account, we conclude that the sequence $\left\{x_{n}\right\}$ is a Cauchy sequence in $(X, d)$. Since the $b$-metric space $(X, d)$ is complete, there exists $u \in X$ such that $\lim _{n \rightarrow+\infty} d\left(x_{n}, u\right)=0$. Due to fact that $\beta<1$, we can easily observe that

$$
\lim _{n \rightarrow+\infty} d\left(x_{n}, x_{n+1}\right)=0,
$$

by using inequality (2.2). Notice that the condition $\left(\mathrm{bms}_{3}\right)$ yields

$$
d\left(x_{n+1}, u\right) \leq s\left(d\left(x_{n+1}, x_{n}\right)+d\left(x_{n}, u\right)\right) .
$$

Consequently, we have

$$
\lim _{n \rightarrow+\infty} d\left(x_{n+1}, u\right)=0 .
$$


In what follows, we shall show that

$$
d(u, F x) \leq \operatorname{srd}(u, x)
$$

for all $x \in X \backslash\{u\}$. Since $d\left(x_{n}, u\right) \rightarrow 0$ as $n \rightarrow+\infty$, there exists $n_{0} \in \mathbb{N}$ such that

$$
d\left(x_{n}, u\right) \leq \frac{1}{3} d(u, x)
$$

for all $n \in \mathbb{N}$ with $n \geq n_{0}$. Then we have

$$
\begin{aligned}
\sigma(r) d\left(x_{n}, F x_{n}\right) & \leq d\left(x_{n}, F x_{n}\right) \leq d\left(x_{n}, x_{n+1}\right) \leq s\left(d\left(x_{n}, u\right)+d\left(u, x_{n+1}\right)\right) \\
& \leq \frac{2 s}{3} d(u, x) \leq s d(u, x)-s d\left(x_{n}, u\right) \\
& \leq s d\left(x_{n}, x\right)
\end{aligned}
$$

and hence by assumption $(2.1)$ we get $H\left(F x_{n}, F x\right) \leq r d\left(x_{n}, x\right)$. Further, we have

$$
\begin{aligned}
d(u, F x) & \leq s\left(d\left(u, x_{n+1}\right)+d\left(x_{n+1}, F x\right)\right) \\
& \leq s\left(d\left(u, x_{n+1}\right)+H\left(F x_{n}, F x\right)\right) \\
& \leq s\left(d\left(u, x_{n+1}\right)+r d\left(x_{n}, x\right)\right) .
\end{aligned}
$$

Letting $n \rightarrow+\infty$ in the inequality above, we obtain

$$
d(u, F x) \leq \operatorname{rsd}(u, x)
$$

for all $x \in X \backslash\{u\}$.

Next, we prove that

$$
H(F x, F u) \leq r d(x, u)
$$

for all $x \in X$ with $x \neq u$. For all $n \in \mathbb{N}$, we choose $v_{n} \in F x$ such that

$$
d\left(u, v_{n}\right) \leq d(u, F x)+\frac{1}{n} d(x, u) .
$$

Then, using (2.3) and the previous inequality, we get

$$
\begin{aligned}
d(x, F x) & \leq d\left(x, v_{n}\right) \leq s\left(d(x, u)+d\left(u, v_{n}\right)\right) \\
& \leq s\left(d(x, u)+d(u, F x)+\frac{1}{n} d(x, u)\right) \\
& \leq\left(d(x, u)+\operatorname{srd}(u, x)+\frac{1}{n} d(x, u)\right) \\
& =s\left(1+s r+\frac{1}{n}\right) d(x, u) .
\end{aligned}
$$


Hence, for all $n \in \mathbb{N}$, we obtain $\sigma(r) d(x, F x) \leq s d(x, u)$. So, we have

$$
H(F x, F u) \leq r d(x, u)
$$

Finally, if for some $n \in \mathbb{N}$ we have $x_{n}=x_{n+1}$, then $x_{n}$ is a fixed point of $F$. Consequently, throughout the proof we assume that $x_{n} \neq x_{n+1}$ for all $n \in \mathbb{N}$. This implies that there exists an infinite subset $J$ of $\mathbb{N}$ such that $x_{n} \neq u$ for all $n \in J$. By Lemma 1, we have

$$
\begin{aligned}
d(u, F u) & \leq s\left(d\left(u, x_{n+1}\right)+d\left(x_{n+1}, F u\right)\right) \\
& \leq s\left(d\left(u, x_{n+1}\right)+H\left(F x_{n}, F u\right)\right) \\
& \leq s\left(d\left(u, x_{n+1}\right)+r d\left(x_{n}, u\right)\right) .
\end{aligned}
$$

Letting $n \rightarrow+\infty$ in the inequality above, with $n \in J$, we find that

$$
d(u, F u)=0 .
$$

By Remark 1, we deduce that $u \in F u$ and hence $u$ is a fixed point of $F$.

Remark 3 Taking $s=1$ in Theorem 2 (it corresponds to the case of metric spaces), the condition on $r<\frac{1}{2}, \sigma(r)=\frac{1}{1+r}$, we find Theorem 1.2 of Kikkawa and Suzuki. Hence, Theorem 2 is an extension of the result of Kikkawa et al. [13], which itself improves the theorem of Nadler [7].

In the case where $T: X \rightarrow X$ is a single-valued mapping on a $b$-metric space, we have the following corollary (it is a consequence of Theorem 2).

Corollary 1 Let $(X, d)$ be a complete b-metric space and let $F: X \rightarrow X$ be a single-valued mapping. Define a strictly decreasing function $\sigma$ from $[0,1)$ onto $\left(\frac{1}{2}, 1\right]$ by $\sigma(r s)=\frac{1}{1+s r}, r<$ $\frac{1}{s^{2}+s}<1$ such that

$$
\sigma(r s) d(x, F x) \leq s d(x, y) \quad \Longrightarrow \quad d(F x, F y) \leq r d(x, y)
$$

for all $x, y \in X$. Then there exists $u \in X$ such that $u=F u$.

Proof It follows by applying Theorem 2 and the fact that $H(F x, F y)=d(F x, F y)$.

Remark 4 Corollary 1 implies the corresponding result of Suzuki [23] if we take $s=1$.

The following theorem is a result of Reich type [8] as well as a generalization of Kikkawa and Suzuki type in the framework of $b$-metric spaces.

Theorem 3 Let $(X, d)$ be a complete b-metric space and let $F: X \rightarrow C B(X)$ be a multivalued mapping. If for $s \geq 1$ there exist nonnegative numbers $a, b, c$ with $s(a+b+c) \in[0,1)$ and $\theta=\frac{1-s b-s c}{1+s a}$ such that

$$
\theta d(x, F x) \leq s d(x, y) \quad \Longrightarrow \quad H(F x, F y) \leq a d(x, y)+b d(x, F x)+c d(y, F y)
$$

for all $x, y \in X$, then $F$ has a fixed point. 
Proof Let $x_{0} \in X$ be arbitrary and $x_{1} \in F x_{0}$, then we have

$$
\theta d\left(x_{0}, F x_{0}\right) \leq \theta d\left(x_{0}, x_{1}\right) \leq s d\left(x_{0}, x_{1}\right)
$$

By condition (2.5) we get

$$
H\left(F x_{0}, F x_{1}\right) \leq a d\left(x_{0}, x_{1}\right)+b d\left(x_{0}, F x_{0}\right)+c d\left(x_{1}, F x_{1}\right)
$$

Let $h \in\left(1, \frac{1}{s(a+b+c)}\right)$, then by Lemma 2 there exists $x_{2} \in F x_{1}$ such that

$$
d\left(x_{1}, x_{2}\right) \leq h H\left(F x_{0}, F x_{1}\right)
$$

which yields

$$
\begin{aligned}
d\left(x_{1}, x_{2}\right) & \leq h H\left(F x_{0}, F x_{1}\right) \leq h\left(a d\left(x_{0}, x_{1}\right)+b d\left(x_{0}, F x_{0}\right)+c d\left(x_{1}, F x_{1}\right)\right) \\
& \leq h(a+b) d\left(x_{0}, x_{1}\right)+h c d\left(x_{1}, x_{2}\right) \\
& \leq \frac{h(a+b)}{1-h c} d\left(x_{0}, x_{1}\right) .
\end{aligned}
$$

Now, we have

$$
\theta d\left(x_{1}, F x_{1}\right) \leq \theta d\left(x_{1}, x_{2}\right) \leq s d\left(x_{1}, x_{2}\right)
$$

Due to assumption (2.1), we get

$$
H\left(F x_{1}, F x_{2}\right) \leq a d\left(x_{1}, x_{2}\right)+b d\left(x_{1}, F x_{1}\right)+c d\left(x_{2}, F x_{2}\right) .
$$

Taking Lemma 2 into account, we conclude that there exists $x_{3} \in F x_{2}$ such that

$$
d\left(x_{2}, x_{3}\right) \leq h H\left(F x_{1}, F x_{2}\right) .
$$

Consequently, we have

$$
\begin{aligned}
d\left(x_{2}, x_{3}\right) & \leq h H\left(F x_{1}, F x_{2}\right) \leq h\left(a d\left(x_{1}, x_{2}\right)+b d\left(x_{1}, F x_{1}\right)+c d\left(x_{2}, F x_{2}\right)\right) \\
& \leq h(a+b) d\left(x_{1}, x_{2}\right)+h c d\left(x_{2}, x_{3}\right) \\
& \leq \frac{h(a+b)}{1-h c} d\left(x_{1}, x_{2}\right) .
\end{aligned}
$$

Continuing in a similar way, we can obtain a sequence $\left\{x_{n}\right\}$ of successive approximations for $F$, starting from $x_{0}$, satisfying the following:

(a) $x_{n+1} \in F x_{n}$ for all $n \in \mathbb{N}$;

(b) $d\left(x_{n}, x_{n+1}\right) \leq k^{n} d\left(x_{0}, x_{1}\right)$ for all $n \in \mathbb{N}$,

where $k=\frac{h(a+b)}{1-h c}<1$. Now, following the lines in the proof of Theorem 2, we deduce that the sequence $\left\{x_{n}\right\}$ converges to some $u \in X$ with respect to the metric $d$, that is, $\lim _{n \rightarrow+\infty} d\left(x_{n}, u\right)=0$. 
For this purpose, we first claim that

$$
d(u, F x) \leq s\left(a+\frac{b}{\theta}\right) d(u, x)+s c d(x, F x)
$$

for all $x \in X \backslash\{u\}$. Since $d\left(x_{n}, u\right) \rightarrow 0$ as $n \rightarrow+\infty$ under the metric $d$, there exists $n_{0} \in \mathbb{N}$ such that

$$
d\left(x_{n}, u\right) \leq \frac{1}{3} d(u, x)
$$

for each $n \geq n_{0}$. Then we have

$$
\begin{aligned}
\theta d\left(x_{n}, F x_{n}\right) & \leq d\left(x_{n}, F x_{n}\right) \leq d\left(x_{n}, x_{n+1}\right) \\
& \leq s\left(d\left(x_{n}, u\right)+d\left(u, x_{n+1}\right)\right) \\
& \leq s\left(\frac{2}{3} d(u, x)\right) \leq s\left(d(u, x)-d\left(x_{n}, u\right)\right) \\
& \leq s d\left(x_{n}, x\right)
\end{aligned}
$$

which implies that

$$
\begin{aligned}
H\left(F x_{n}, F x\right) & \leq a d\left(x_{n}, x\right)+b d\left(x_{n}, F x_{n}\right)+c d(x, F x) \\
& \leq a d\left(x_{n}, x\right)+\frac{b}{\theta} d\left(x_{n}, x\right)+c d(x, F x) \\
& =\left(a+\frac{b}{\theta}\right) d\left(x_{n}, x\right)+c d(x, F x)
\end{aligned}
$$

for all $n \geq n_{0}$. Thus we have

$$
\begin{aligned}
d(u, F x) & \leq s\left(d\left(u, x_{n+1}\right)+d\left(x_{n+1}, F x\right)\right) \\
& \leq s\left(d\left(u, x_{n+1}\right)+H\left(F x_{n}, F x\right)\right) \\
& \leq s\left(d\left(u, x_{n+1}\right)+\left(a+\frac{b}{\theta}\right) d\left(x_{n}, x\right)+c d(x, F x)\right)
\end{aligned}
$$

for all $n \geq n_{0}$. Letting $n \rightarrow+\infty$, we get

$$
d(u, F x) \leq s\left(a+\frac{b}{\theta}\right) d(u, x)+\operatorname{scd}(x, F x)
$$

for all $x \in X \backslash\{u\}$.

Next, we show that

$$
H(F x, F u) \leq\left(a+\frac{b s}{\theta}\right) d(x, u)+c d(u, F u)
$$

for all $x \in X$ with $x \neq u$. Now, for all $n \in \mathbb{N}$, there exists $y_{n} \in F x$ such that

$$
d\left(u, y_{n}\right) \leq d(u, F x)+\frac{1}{n} d(x, u)
$$


On the other hand, we have

$$
\begin{aligned}
d(x, F x) & \leq d\left(x, y_{n}\right) \leq s\left(d(x, u)+d\left(u, y_{n}\right)\right) \\
& =s\left(d(x, u)+d\left(u, y_{n}\right)\right) \\
& \leq s\left(d(x, u)+d(u, F x)+\frac{1}{n} d(x, u)\right) \\
& \leq s\left(d(x, u)+s\left(a+\frac{b}{\theta}\right) d(u, x)+c d(x, F x)+\frac{1}{n} d(x, u)\right) \\
& =s\left(1+s a+\frac{s b}{\theta}+\frac{s}{n}\right) d(x, u)+s c d(x, F x)
\end{aligned}
$$

for all $n \in \mathbb{N}$. Letting $n \rightarrow+\infty$ in the inequality above, we derive that

$$
(1-s c) d(x, F x) \leq s\left(1+s a+\frac{s b}{\theta}\right) d(x, u)
$$

Hence, we have $\theta d(x, F x) \leq s d(x, u)$, which implies

$$
\begin{aligned}
H(F x, F u) & \leq a d(x, u)+b d(x, F x)+c d(u, F u) \\
& \leq\left(a+\frac{b s}{\theta}\right) d(x, u)+c d(u, F u)
\end{aligned}
$$

for all $x \in X \backslash\{u\}$.

Finally, if for some $n \in \mathbb{N}$ we have $x_{n}=x_{n+1}$, then $x_{n}$ is a fixed point of $F$. Assume that $x_{n} \neq x_{n+1}$ for all $n \in \mathbb{N}$. Thus, there exists an infinite subset $J$ of $\mathbb{N}$ such that $x_{n} \neq u$ for all $n \in J$. Now, for all $n \in J$, we have

$$
\begin{aligned}
d(u, F u) & \leq s\left(d\left(u, x_{n+1}\right)+d\left(x_{n+1}, F u\right)\right) \\
& \leq s\left(d\left(u, x_{n+1}\right)+H\left(F x_{n}, F u\right)\right) \\
& \leq s\left(d\left(u, x_{n+1}\right)+\left(a+\frac{s b}{\theta}\right) d\left(x_{n}, u\right)+c d(u, F u)\right) .
\end{aligned}
$$

Letting $n \rightarrow+\infty$ with $n \in J$, we get

$$
d(u, F u)=0 .
$$

By Remark 1, we deduce that $u \in F u$ and hence $u$ is a fixed point of $F$.

Remark 5 Taking $s=1$ in Theorem 3 (it corresponds to the case of metric spaces), with $a+b+c \in[0,1), \theta=\frac{1-b-c}{1+a}$, we get Theorem 6.6 of Mot and Petrusel [14] which itself is an extension of the theorem given in Reich [8], p.5, as well as a generalization of KikkawaSuzuki's Theorem 1.1.

If $T: X \rightarrow X$ is a single-valued mapping on a $b$-metric space, we have the following corollary which is a consequence of Theorem 3. 
Corollary 2 Let $(X, d)$ be a complete $b$-metric space and let $F: X \rightarrow X$ be a single-valued mapping. If for $s \geq 1$ there exist nonnegative numbers $a, b, c$ with $s(a+b+c) \in[0,1)$ and $\theta=\frac{1-s b-s c}{1+s a}$ such that

$$
\theta d(x, F x) \leq s d(x, y) \quad \Longrightarrow \quad d(F x, F y) \leq a d(x, y)+b d(x, F x)+c d(y, F y)
$$

for all $x, y \in X$, then $F$ has a fixed point.

Remark 6 If we take $s=1$ in Corollary 2, we immediately get a Kikkawa-Suzuki type fixed point theorem for a Reich-type single-valued operator, see [8, 24].

Example 2 Let $X=[1, \infty)$ and $d(x, y)=|x-y|^{2}$ for all $x, y \in X$. Then $d$ is a $b$-metric on $X$ with $s=2$ and $(X, d)$ is complete. Also, $d$ is not a metric on $X$. Define $F: X \rightarrow C B(X)$ by

$$
F x=\left[2,2+\frac{x}{3}\right]
$$

for all $x, y \in X$. Consider $H(F x, F y)=\frac{1}{9}(x-y)^{2}=\frac{1}{9} d(x, y)$, where $r=\frac{1}{9}<\frac{1}{6}=\frac{1}{s^{2}+s}<1$. So all the conditions of Theorem 2 are satisfied. Moreover, 2 and 3 are the two fixed points of $F$.

Competing interests

The authors declare that there is no conflict of interests regarding the publication of this article.

Authors' contributions

All authors contributed equally and significantly in writing this article. All authors read and approved the final manuscript.

\section{Author details}

${ }^{1}$ Department of Mathematics, King Abdulaziz University, P.O. Box 80203, Jeddah, 21589, Saudi Arabia. ${ }^{2}$ Department of Mathematics, Atilim University, İncek, Ankara 06836, Turkey. ${ }^{3}$ Nonlinear Analysis and Applied Mathematics Research Group (NAAM), King Abdulaziz University, Jeddah, Saudi Arabia. ${ }^{4}$ Department of Mathematics COMSATS, Institute of Information Technology, Chack Shahzad, Islamabad, 44000, Pakistan.

\section{Acknowledgements}

First author gratefully acknowledges the support from the Deanship of Scientific Research (DSR) at King Abdulaziz University (KAU) during this research. The third author gratefully acknowledges the support from the Higher Education Commission of Pakistan. The authors thank the anonymous referees for their remarkable comments, suggestions and ideas that helped to improve this paper.

\section{Received: 1 November 2013 Accepted: 17 March 2014 Published: 28 Mar 2014}

\section{References}

1. Czerwik, S: Contraction mappings in b-metric spaces. Acta Math. Inform. Univ. Ostrav. 1, 5-11 (1993)

2. Banach, S: Sur les opérations dans les ensembles abstraits et leur application aux équations intégrales. Fundam. Math. 3, 133-181 (1922)

3. Azam, A, Mehmood, N, Ahmad, J, Radenović, S: Multivalued fixed point theorems in cone $b$-metric spaces. J. Inequal. Appl. 2013, Article ID 582 (2013)

4. Czerwik, S, Dlutek, K, Singh, SL: Round-off stability of iteration procedures for operators in b-metric spaces. J. Natur. Phys. Sci. 11, 87-94 (1997)

5. Czerwik, S: Nonlinear set-valued contraction mappings in b-metric spaces. Atti Semin. Mat. Fis. Univ. Modena 46(2), 263-276 (1998)

6. Hussain, N, Shah, MH: KKM mappings in cone b-metric spaces. Comput. Math. Appl. 62(4), 1677-1684 (2011)

7. Nadler, S: Multi-valued contraction mappings. Pac. J. Math. 20,475-488 (1969)

8. Reich, S: Fixed points of contractive functions. Boll. Unione Mat. Ital. 5, 26-42 (1972)

9. Aydi, H, Bota, M-F, Karapınar, E, Moradi, S: A common fixed point for weak- $\phi$-contractions on $b$-metric spaces. Fixed Point Theory 13(2), 337-346 (2012)

10. Boriceanu, M: Strict fixed point theorems for multivalued operators in b-metric spaces. Int. J. Mod. Math. 4(2), 285-301 (2009)

11. Bota, M-F, Karapınar, E, Mlesnite, O: Ulam-Hyers stability results for fixed point problems via alpha-psi-contractive mapping in b-metric space. Abstr. Appl. Anal. 2013, Article ID 825293 (2013) 
12. Bota, M-F, Karapınar, E: A note on 'Some results on multi-valued weakly Jungck mappings in b-metric space'. Cent. Eur. J. Math. 11, 1711-1712 (2013)

13. Kikkawa, M, Suzuki, T: Three fixed point theorems for generalized contractions with constants in complete metric spaces. Nonlinear Anal. 69, 2942-2949 (2008)

14. Mot, G, Petrusel, A: Fixed point theory for a new type of contractive multi-valued operators. Nonlinear Anal. 70 , 3371-3377 (2009)

15. Dhompongsa, S, Yingtaweesittikul, H: Fixed points for multi-valued mappings and the metric completeness. Fixed Point Theory Appl. 2009, Article ID 972395 (2009)

16. Boriceanu, M: Fixed point theory for multivalued generalized contraction on a set with two $b$-metrics. Stud. Univ. Babeş-Bolyai, Math. LIV(3), 1-14 (2009)

17. Bota, M, Molnar, A, Varga, C: On Ekeland's variational principle in b-metric spaces. Fixed Point Theory 12(2), 21-28 (2011)

18. Singh, SL, Prasad, B: Some coincidence theorems and stability of iterative procedures. Comput. Math. Appl. 55 2512-2520 (2008). doi:10.1016/j.camwa.2007.10.026

19. Păcurar, M: Sequences of almost contractions and fixed points in b-metric spaces. An. Univ. Vest. Timiş., Ser. Mat.-Inform. XLVIII(3), 125-137 (2010)

20. Pacurar, M: A fixed point results for $\varphi$-contractions on $b$-metric spaces without the boundedness assumption. Fasc Math. 43, 127-137 (2010)

21. Aydi, H, Bota, MF, Karapınar, E, Mitrović, S: A fixed point theorem for set-valued quasicontractions in $b$-metric spaces. Fixed Point Theory Appl. 2012, Article ID 88 (2012)

22. Singh, SL, Czerwik, S, Krol, K, Singh, A: Coincidences and fixed points of hybrid contractions. Tamsui Oxford Univ. J. Math. Sci. 24, 401-416 (2008)

23. Suzuki, T: A generalized Banach contraction principle that characterizes metric completeness. Proc. Am. Math. Soc. $136,1861-1869(2008)$

24. Reich, S: Kannan's fixed point theorem. Boll. Unione Mat. Ital. 4, 1-11 (1971)

10.1186/1029-242X-2014-126

Cite this article as: Kutbi et al.: Some fixed point results for multi-valued mappings in $b$-metric spaces. Journal of Inequalities and Applications 2014, 2014:126

\section{Submit your manuscript to a SpringerOpen ${ }^{\circ}$ journal and benefit from:}

- Convenient online submission

Rigorous peer review

- Immediate publication on acceptance

- Open access: articles freely available online

- High visibility within the field

- Retaining the copyright to your article 